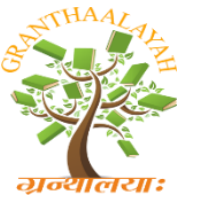

INTERNATIONAL JOURNAL OF RESEARCH GRANTHAALAYAH A knowledge Repository

RAST - 17

\title{
FOOD QUALITY MANAGEMENT AND SAFETY
}

\author{
Rizwana Khatoon $^{1}$, Debkumar Chakraborty ${ }^{* 2}$, R.C. Chandni ${ }^{3}$, Amar Sankar ${ }^{4}$, A.V. \\ Raghu $^{* 5}$ \\ $1, * 2,3,4,{ }^{* 5}$ Center of Emerging Technology, Department of Food Technology, School of \\ Engineering Technology, Jain University 560 078, India
}

DOI: https://doi.org/10.29121/granthaalayah.v5.i4RAST.2017.3312

\begin{abstract}
Food safety system mainly focuses on identifying and preventing hazards that may lead product to deteriorate. The main important of manufacturing practice is a system that ensures that products meet food safety, quality and legal requirements. The hazard analysis and critical control point system, applies to food safety management, uses the approach of controlling critical points in food handling to prevent food safety problems. Besides enhancing food safety, other benefits of applying HACCP include effective use of resources and timely response to food safety problems. In addition HACCP can be part of GMP and is a systematic program to assure food safety. It is important to know to what extent the systems contribute to the total quality of the product and to balance the tools used for achieving the quality and safety objectives.
\end{abstract}

Keywords: Food Safety; Good Manufacturing Practices (GMP); Hazard Analysis Critical Control Points (HACCP); Food Safety Management.

Cite This Article: Rizwana Khatoon, Debkumar Chakraborty, R.C. Chandni, Amar Sankar, and A.V. Raghu. (2017). "FOOD QUALITY MANAGEMENT AND SAFETY." International Journal of Research - Granthaalayah, 5(4) RAST, 116-121. https://doi.org/10.29121/granthaalayah.v5.14RAST.2017.3312.

\section{Introduction}

Adoption of GMP (Good Manufacturing Practices), GHP (Good Handling Practices), HACCP (Hazard Analysis and Critical Control Point) and other such practices to be followed by Food Business Operators (FBOs) is known as Food safety management system (FSMS) which can be used to ensure food safety. The FSMS programme which cannot be separated from Food Safety helps FBOs to ensure that food is safe for human consumption. Food Safety and Standards Authority of India (FSSAI) has considered the FSMS programme as regulations and asked FBOs to follow it. License would not be available unless the FBO provides details of the FSMS programme to FSSAI. Food industry is one of the fastest growing industries in India and around the world. Shelf life of food products varies from product to product with regard to temperature 
and humidity, types of possible interaction between products, time for delivering the products etc. Because of high expectations from customer and low profit margins make food distribution management a challenging task which has recently began to receive more attention in the operations management literature. Available Quality Assurance (QA) systems in India are Good Manufacturing Practices (GMPs), GHPs (Good Hygiene Practices), GAPs (Good Agricultural Practices) or other prerequisite systems and HACCP.

\section{Food Safety Programme}

A food safety program covers all aspects of food service in industry business and has produces for each food process step to keep food safe. It includes cleaning, staff health and hygiene, staff training, documentation, waste management.

\subsection{HACCP System}

HACCP is a preventative, proactive and systematic approach of food safety, which relies on the identification and control of the all the known associated health hazards in the food chain. This HACCP system is science based and systematic, synonymous specific hazards and measures for their control to ensure the safety of food and management system. It is important to identify the possible hazards that can occur at every stage of the food business and food sectors from growth, manufacturing, production, retailer, exporter storage and distribution, until the point where it is sold to the consumer. The system based on seven principles (2-7) was developed to control the biological, chemical, and physical hazards from the raw material production, through manufacturing, distribution and consumption of the finished product (Figure 1). Food must be considered as safe for consumption if they fulfill legislative requirements; technological criteria; hygiene requirements; transport and handling requirements; trading conditions.

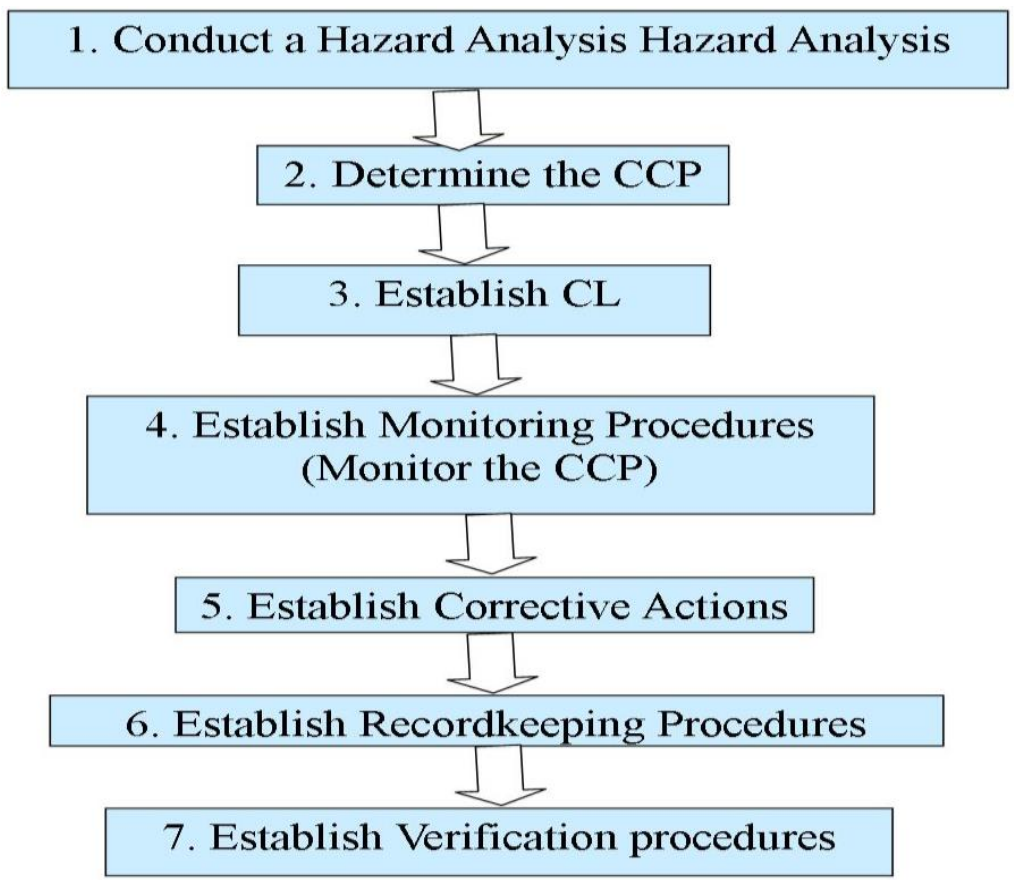

Figure 1: Principles of HACCP Plan 


\subsection{GMP System}

GMP covers all aspects of production from the starting materials, premises and equipment to the training and personal hygiene of staff. General requirements for food safety assurance are described in Table 1. Company's responsibility is to determine the most effective and efficient quality process.

Table 1: General requirement for food safety assurance in the food industry

\begin{tabular}{|l|l|}
\hline Staff & $\begin{array}{l}\text { Create an appropriate organizational framework, describe the key positions, } \\
\text { train the workers, develop behavioral and attitude competencies supervise } \\
\text { personal hygiene and health etc. }\end{array}$ \\
\hline self-inspection & Perform internal audit, check compliance and corrective action etc. \\
\hline $\begin{array}{l}\text { Quality } \\
\text { control }\end{array}$ & $\begin{array}{l}\text { Apply good practices in the laboratory, apply sampling techniques, validate the } \\
\text { analytical method, inspect the process, maintain, check and calibrate the } \\
\text { measuring and monitoring devices. }\end{array}$ \\
\hline processing & $\begin{array}{l}\text { Validate the processes, prevent cross-contamination during manufacture, } \\
\text { purchase good raw material, ensure the quality of the process, for intermediate, } \\
\text { bulk or end products, comply legal labeling requirements, ensure good quality } \\
\text { of the end products (quarantine, storage, handling, delivery), track the products } \\
\text { rejected recovered and returned (tracking and identification) etc. }\end{array}$ \\
\hline $\begin{array}{l}\text { Consumer } \\
\text { complaints }\end{array}$ & $\begin{array}{l}\text { Handle the complaints, document the withdrawals / recalls, analyze the } \\
\text { decisions. }\end{array}$ \\
\hline Warehousing & $\begin{array}{l}\text { Warehousing involves three activities (receiving, storage and shipping) that are } \\
\text { included in a quality control program. }\end{array}$ \\
\hline Regulations & Apply mandatory requirements, follow contractual requirements. \\
\hline
\end{tabular}

\subsection{Food Distribution Systems}

Physical flows and storage of products from the final production point to the customer or end user is known as distribution management process (Rushton et al. 2006). After procuring agricultural raw materials, food manufacturers process those before further distribution. The processing step includes ranging from simple packaging of fresh produce to extensive cooking or preservation operations. General conditions according to the HACCP Guide for Good Sanitary Practice in transportation are as follows.

1) Means of transport have to be constructed in a way to enable efficient cleaning and disinfection; they must be physically separated in order to prevent contamination.

2) Needs to be at a specific temperature level, have to ensure proper temperature control.

\subsection{Food Safety}

The food distribution system was shown in Figure 2. Food safety generally refers to the prevention of illnesses resulting from the consumption of contaminated food. In 2000 food borne diseases emerged which decreased consumers and public confidence across Europe and the European Union started changing food safety approach The European Union decided to establish a unique legislation for all the member states regarding food safety in which they 
recommended a scientific assessment of risk with strict procedures. A well-known example of such a food safety crisis is the recent recall of peanut butter in the USA due to the presence of salmonella. It was the largest product recall ever in the history of the country, involving more than 200 food manufacturers downstream in the supply chain - in total recalling more than 2100 products (Terreri, 2009).

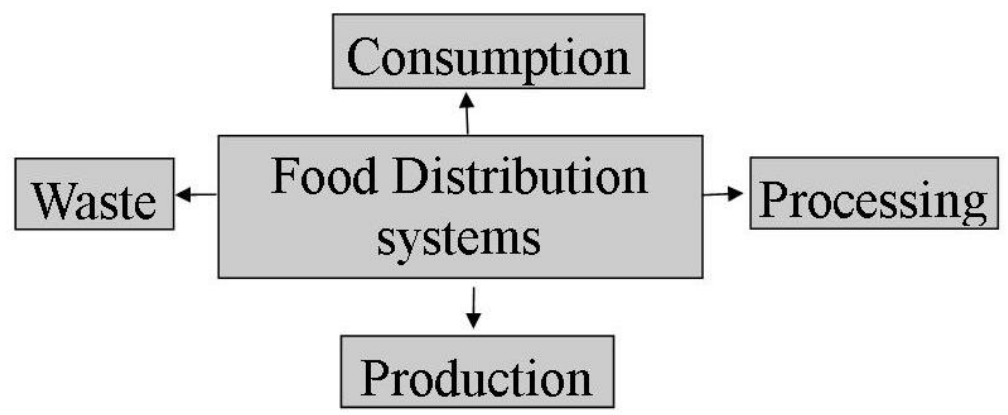

Figure 2: Food distribution system

One of the most important food safety protection policies was labeling of foods which are very important in order to protect the rights of consumers on the market. Labeling of foods includes its origins, preservation process, preparation techniques and its shelf-life. All equipment and materials used have to be regularly maintained and installed as to enable easier cleaning and disinfection, as well as appropriate control devices for measuring temperature, pressure etc.

\subsection{Food Quality}

Food quality is not only refers to the physical properties of food products, but also on the way the product is perceived by the final consumer (Grunert, 2005). This includes microbial aspects, texture and flavor. Quality assurance dominates the process of production, distribution and the costs for certification, auditing. It also evokes responses like technological innovation to create higher efficiency and reduce costs. New technological developments such as time-temperature integrators or indicators can be used to improve temperature monitoring throughout the distribution system (Giannakourou and Taoukis, 2003). This allows improved shelf life estimation of food products e.g. Pork, poultry and fish chains (Dalgaard et al. 2002; Raab et al. 2008). The most important quality monitoring systems in the food industry are: Global Food Safety Initiative (GSFI), International Food Standard (IFS), International Organization for Standardization (ISO), Safe Quality Food (SQF) and British Retail Consortium (BRC). The aim of these norms is to help the retailers to ensure safety of their products and food quality monitoring.

\section{Food Safety Control System}

HACCP represents an integrated system of food safety control in all the phases of its production and distribution (Figure 3). It was developed in the USA in 1960 as a help in food preparation for astronauts, and is also one of the first systems for food safety control widely accepted in food processing. There are two main components to HACCP: Hazard Analysis (HA) and Critical Control Points (CCP). Hazard Analysis (HA) is a risk analysis with which dangers at every stage of production and delivery and it evaluates the levels of those dangers and how they affect 
human health. Critical Control Points (CCP) in the food chain are those points which enable complete prevention or elimination of risks or at least reduction of risks onto an acceptable level, as well as their control to ensure food safety. Five branches of food industry demanding the implementation of the HACCAP system are production, processing, storage, transport, distribution.

The first safety is security of food source (food security), important in the underdeveloped countries, while the second safety is the one related to the sanitary correctness (food safety). One of the elements of the food safety relates to the legislation enforcement and food control, and is performed by the system of rapid information on food for humans and animals RASFF (Rapid Alert System for Food and Feed) which enables rapid flow of information about new risks. Product changes are often reduced by temperature-controlled storage and distribution, which, however, normally require a significant amount of energy, there by negatively affecting the environmental impact of the products (James and James, 2010). Twinn in 2007 discussed the challenges the cold storage and distribution sector faces with respect to environmental concerns and increasing electricity costs. Nowadays, systems that are originally designed to control food safety (e.g. HACCP) are also used to increase the product quality throughout the supply chain (Panozzo et. al. 1999). This also concerns nutritional quality, as can for instance be seen in the recent development of the nutritional control points (NCP) concept (Rodrigues et. al. 2010). This is based on the HACCP system, and can be used to identify the critical points in production and distribution systems related to nutritional product changes and eventually help to increase nutritional quality.

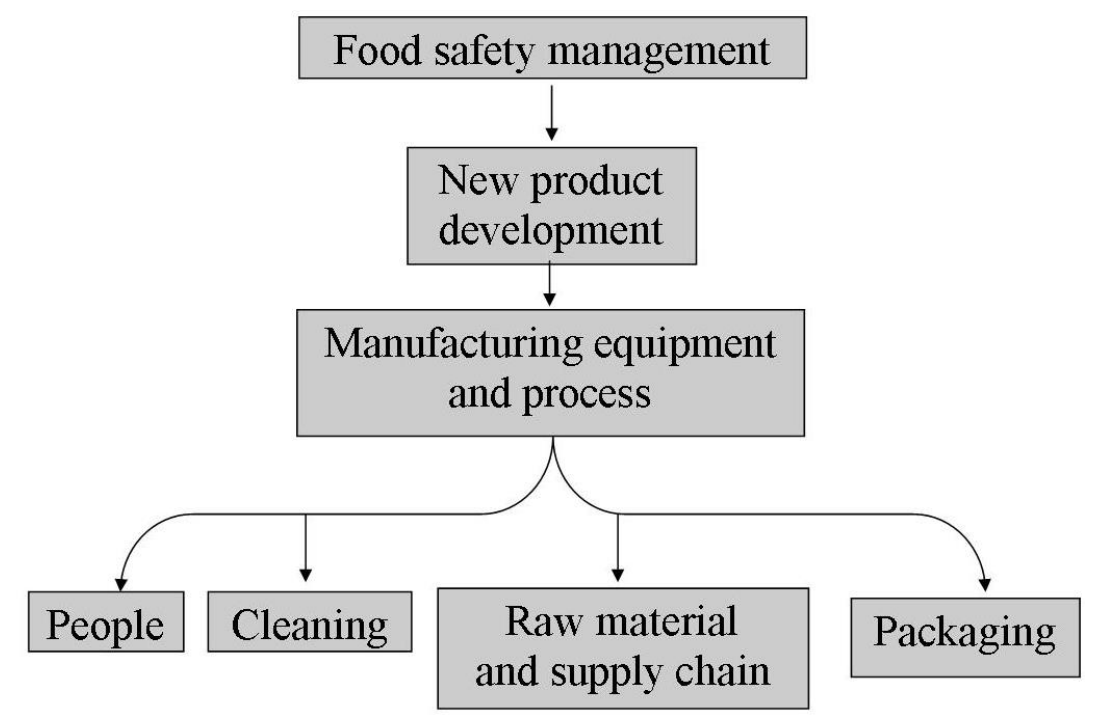

Figure 3: Food safety management system.

\section{Conclusion}

Overall tools for use in an integrated approach to the management of food safety are described in this report. They comprise the use of elements of Good manufacturing Practice (GMP) that are specifically concerned with the general design and operation of hygienic premises and equipment and with the hygiene of personnel, GMP requirements associated with hygiene form the basis for the operation of a hygienic food operation. Food Safety, HACCP and other Quality management 
System looks for hazards or anything that could go wrong regarding product safety and implements controls subsequently to ensure that the product will not cause harm to the consumer. Food products go through every stage of the supply chain (production, storage and sales). The document gives the interrelationship between risk analysis (i.e., risk assessment, risk management and risk communication) and HACCP.

\section{References}

[1] Twinn F (2007) Energy reduction becomes a priority. Food Manufacture 82(3): 41-42.

[2] James SJ, and James C (2010) Advances in the cold chain to improve food safety, food quality and the food supply chain. In: Mena C, Stevens G (Eds) Delivering performance in food supply chains.

[3] Rodrigues CMA, Della Lucia CM, Azeredo RMC, Cota AM, Santana AMC, PinheiroSantana HM (2010) Control of vitamin C losses in vegetables prepared at a food service. Food Control 21(3): 264-271.

[4] Terreri A (2009) Preventing the next product recall. Food Logist 111:20-25.

[5] Giannakourou MC, Taoukis PS (2003) Application of a TTI-based distribution management system for quality optimization of frozen vegetables at the customer end. J Food Sci 68(1):201-209.

[6] Dalgaard P, Buch P, Silberg S (2002) Seafood spoilage predictor-development and distribution of a product application software. Int. J Food Microbiol 73(2-3):343-349.

[7] Grunert KG (2005) Food quality and safety: consumer perception and demand. Eur Rev Agri Econ 32(3):369-391.

[8] Raab V, Bruckner S, Beierle E, Kampmann Y, Petersen B, Kreyenschmidt J (2008) Generic model for the prediction of remaining shelf life in support of cold chain management in pork and poultry supply chains. J Chain Network Sci 8(1):59-73.

[9] Panozzo G, Minotto G, Barizza A (1999) Transport and distribution of foods: today's situation and future trends. Int J Refrigerat 22(8):625-639.

[10] Rushton A, Croucher P, Baker P (2006) The Handbook of Logistics and Distribution Management, 3rd Edn. Kogan Page, London, UK.

\footnotetext{
*Corresponding author.

E-mail address: gsraghu2003@yahoo.co.in
} 